\title{
El pop como síntoma: Disonancias entre el jazz y el videoclip contemporáneo
}

\author{
Marcelo Jaume
}

\author{
Recibido: 26.09.2019 - Aceptado: 17.10.2019
}

\section{Titre / Title / Titolo}

Musique Pop comme symptôme: Disonances entre jazz et vidéoclip contemporain

Pop music as a symptom: Dissonances between jazz and contemporary videoclip

Il pop come sintomo. Dissonanze tra jazz e videoclip contemporaneo

\section{Resumen / Résumé / Abstract / Riassunto}

El jazz tiene en la actualidad, especialmente desde su establecimiento en el ámbito académico a finales de la década de 1980, una posición ambigua respecto a la música popular. Esta particular demarcación resulta también patente en su anómala relación con el videoclip, narrativa dominante en la música popular y donde el jazz no tiene un espacio de representación habitual, pese a su protagonismo en otras épocas a través de formatos como soundies y scopitones. A pesar de ser relativamente frecuentes las grabaciones de conciertos y teasers promocionales, el videoclip como discurso estético autónomo no está extendido. El objetivo principal de este texto es examinar críticamente los motivos de esta particular relación, con especial atención al caso europeo. Para ello, se analizarán ejemplos y se considerarán cuestiones como las nociones de relato y narratividad asociadas a la música instrumental, los discursos superpuestos a esta desde el medio visual, la autonomía del lenguaje del videoclip y la relación entre el jazz y otros géneros musicales.

Le jazz a de nos jours, surtout depuis sa mise en place dans le domaine universitaire à la fin des années 1980, une position ambiguë vis-à-vis de la musique populaire. Cette démarcation particulière est également évidente dans sa relation anormale avec la vidéo musicale, récit dominant dans la musique populaire et où le jazz n'a pas d'espace de représentation habituel, malgré sa prédominance autrefois à travers les formats comosoundies et scopitones. Bien que l'enregistrement de concerts et teasers promotionels restent relativement fréquents, le clip musicale en tant que discours esthétique autonome, n'est pas répandu. Le but principal de ce texte est d'examiner de manière critique les raisons de cette relation particulière, en accordant spécialement attention au cas européen. Pour cela, des exemples seront analysés et des questions telles que les notions de récit et narrative associées à la musique instrumentale, les discours qui s'y superposent à partir du support visuel, l'autonomie du langage du clip vidéo et la relation entre le jazz et d'autres genres musicaux, seront considérées.
Jazz has today, especially since its establishment in the academic field at the end of the 1980s, an ambiguous position regarding popular music. This particular demarcation is also evident in its anomalous relationship with the videoclip, the dominant narrative in popular music and where jazz does not have a usual representational space, despite its previous prominence through formats such as soundies and scopitones. In defiance of the relatively frequent video recordings of concerts and promotional teasers, the videoclip as an autonomous aesthetic discourse is not widespread. The main objective of this text is to examine critically the reasons for this relationship, with special attention to the European context. For this purpose, I will analyze several examples and consider issues such as the notion of narrative associated with instrumental music, the autonomy of video clip language and the relationship between jazz and other musical genres.

Il jazz ha oggi, soprattutto dalla sua istituzione nel campo accademico alla fine degli anni '80, una posizione ambigua rispetto alla musica popolare. Questa particolare demarcazione è anche evidente nella sua relazione anomala con il videoclip, la narrativa dominante nella musica popolare e in cui il jazz non ha uno spazio di rappresentazione abituale, nonostante la sua importanza in altri momenti attraverso formati come soundies e scopitoni. A dispetto delle registrazioni video relativamente frequenti di concerti e teaser promozionali, il videoclip come discorso estetico autonomo non è molto diffuso. L'obiettivo principale di questo testo è quello di esaminare criticamente le ragioni di questa particolare relazione, con particolare attenzione al caso europeo. A tal fine, analizzerò diversi esempi e considererò questioni come la nozione di narrativa associata alla musica strumentale, l'autonomia del linguaggio del videoclip e il rapporto tra il jazz e altri generi musicali.

\section{Palabras clave / Mots-clé I Key words / Parole chiave}

Música pop, jazz, videoclip, síntoma.

Musique pop, jazz, vidéoclip, symptôme.

Pop music, jazz, videoclip, symptom.

Musica pop, jazz, videoclip, sintomo. 
El símbolo de la casa tomada, referida por Cortázar en su relato homónimo, funciona especialmente bien si lo aplicamos a la presencia del jazz en el audiovisual. El audiovisual, un espacio de aproximadamente un siglo de antigüedad que desde sus inicios fue habitado por el jazz en películas, soundies o scopitones, ha ido llenando sus estancias de otras músicas hasta dejarlo en las afueras del videoclip, uno de sus principales discursos contemporáneos. Por ello, no resulta extraño comprobar que intérpretes ampliamente reconocidos como Kenny Garrett, Jason Moran o Christian Scott (Atunde Adjuah) ni siquiera tienen un canal en YouTube ${ }^{1}$. ¿A qué se debe este exilio o ausencia, acentuado al compararlo con la centralidad del videoclip en la mayoría de géneros musicales? El siguiente texto orbita alrededor de esta cuestión. Para tratar de enunciarla mejor y ofrecer, al menos, alguna hipótesis provisional, nos referiremos a la idea de relato respecto al videoclip, a las particularidades del jazz con incidencia en sus narrativas audiovisuales y a cierto discurso estético neoclásico asumido por el jazz que determina de igual manera su relación con el vídeo musical. Por último, glosaremos algunos ejemplos que ponen de manifiesto los vínculos entre el videoclip del jazz y los de géneros como el pop y el rap.

\section{El espacio del relato en el videoclip}

Para abordar la definición del jazz, habitualmente problemática, adoptaremos una actitud similar a la de Dino Formaggio respecto al arte (1976: 11) y consideraremos jazz «todo aquello a lo que se ha llamado jazz». El motivo principal de esta laxitud es que, debido a nuestro propósito, es conveniente referirnos a artistas como Jamie Cullum, US3 o Saint Germain, en la intersección entre el jazz y otros géneros musicales como el pop, el rap o la electrónica. Respecto al videoclip, a diferencia del jazz, necesitamos trazar una delimitación, por

\footnotetext{
${ }^{1}$ Nos referimos aquí a canales creados específicamente por el artista o discográfica, no a aquellos canales-tema generados automáticamente por YouTube que recopilan vídeos subidos por diversos usuarios.
}

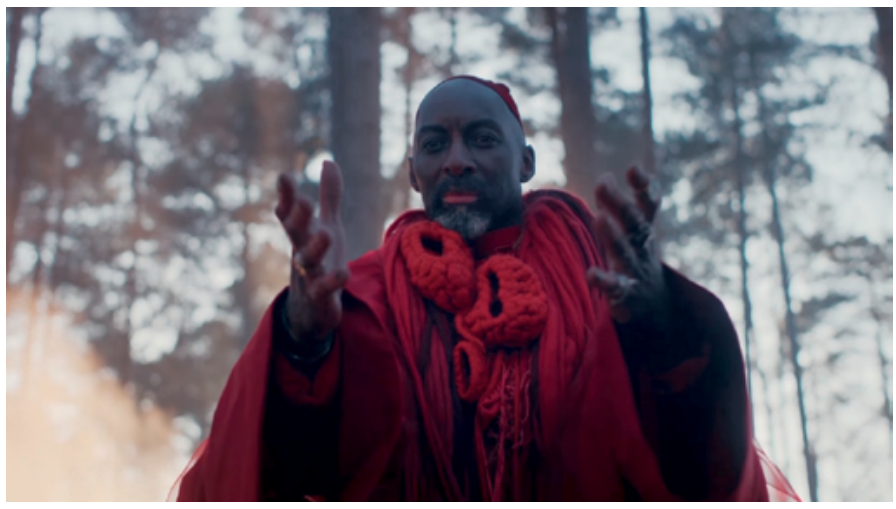

«Space Travellers Lullaby» (Kamasi Washington, 2018).

provisional que sea, que oriente nuestras reflexiones. Consideraremos un videoclip toda aquella representación audiovisual que, partiendo de un registro musical, superponga a este un discurso visual nuevo. Por contra, no consideraremos videoclips aquellas interpretaciones grabadas - ya sean en vivo o simuladas - cuyo contenido visual sea la interpretación misma. En el ámbito anglosajón esta tipología audiovisual se conoce como performance video, nombre con el que nos referiremos a ella partir de ahora ${ }^{2}$. De esta manera, serían videoclips «Hub-tones» (Kamasi Washington, 2018) o «Space Travelers Lullaby» (Kamasi Washington, 2018) a diferencia de aquellos performance videos - la serie Live at Capitol (Robert Glasper, 2015), por ejemplo-que constituyen el grueso de los canales de YouTube de artistas como Wynton Marsalis o Snarky Puppy ${ }^{3}$.

Resulta evidente que en la mayoría de videoclips está presente la interpretación por parte del artista o grupo 4 pero, como hemos señalado, la condición que los diferencia de un performance video es la superposición de un discurso visual nuevo, que puede presentar multitud de posibilidades. Desde el mero tránsito del artista mientras se desarrolla la canción («Bitter Sweet

\footnotetext{
${ }^{2}$ Los performance videos suelen realizarse sin público, a diferencia de un live video.

${ }^{3}$ A la pregunta sobre la utilidad de esta distinción entre performance video y videoclip o vídeo musical, formatos audiovisuales colindantes como hemos visto, cabe responder que nos ayudará a poner en perspectiva las diferencias entre las actuaciones de Robert Glasper y Yussef Kamaal para Brownswood y NPR Music frente a sus vídeos musicales «Ghetto Walkin'« (2016) y «Salaam» (2018), por ejemplo.

${ }^{4}$ A pesar de de ello, hay numerosas excepciones, como «Kids» (MGMT, 2008), «Unfinished Sympathy» (Massive Attack, 1991), «Smack my Bitch Up» (Prodigy, 1997) o «Turn Down for What» (Dj Snake y Lil Jon, 2014).
} 


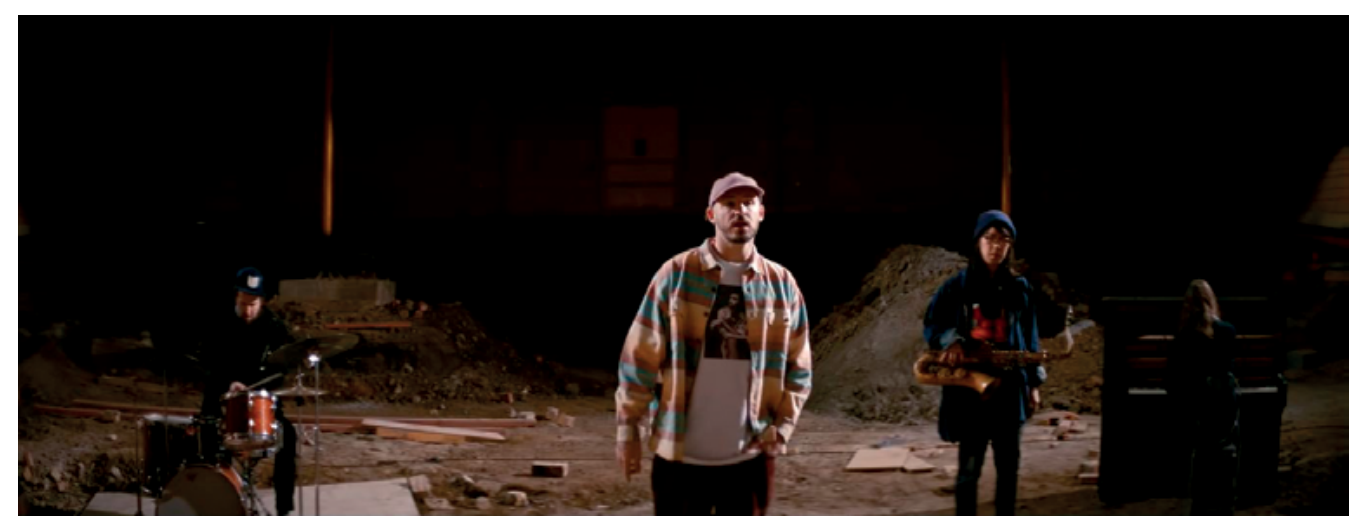

«Years gone by» (Avantdale Bowling Club, 2018).

Symphony» [The Verve, 997] o «Someone Like You» [Adele, 2011]) a la presentación de un relato paralelo a la música ${ }^{5}$, posiblemente uno de los recursos más habituales, como en el caso de «Sonne» (Rammstein, 2015) o «Bad Motherfucker» (Biting Elbows , 2013). La frontera entre performance video y videoclip es en ocasiones tenue y se define por el lugar donde esta tiene lugar («Years gone by» [Avantdale Bowling Club, 2018]), hechos extramusicales (el final de la propia «Years gone by» o «You Only Live Once» [The Strokes, 2006]) o el tratamiento distintivo de la imagen, como en «I Bet You Look Good on the Dancefloon» (Arctic Monkeys, 2005), que se grabó utilizando cámaras Ikegami de la década de $1980^{\circ}$.

$\mathrm{Al}$ afirmar, como hemos hecho, que a menudo los videoclips presentan un relato paralelo a la música, cabe preguntarse si podemos considerar la música otro relato superpuesto al visual. La problemática surge en la propia definición de relato, pues si lo consideramos como un conjunto de acontecimientos que conforman un discurso cerrado al margen del aquí y ahora del receptor y que es reconocido por él como tal (se ha sintetizado la definición de Metz citada en Gaudreault y Jost, 1995: 26-29), tendremos dificultades para relacionar la noción de «acontecimientos» con la música. Y no porque en su producción no tengan lugar (efectivamente, para que un piano suene alguien debe apretar las teclas), sino porque estos quedan fuera en una escucha en diferido. Aunque la manera de producir sentido de la música hace complicado asimilarla a cualquier tipo de discurso narrativo cercano al relato, este aparente vacío semántico lo ocupa a menudo un texto ${ }^{7}$ que dota a la música de nexos estables con significados externos a ella.

\section{Acerca de la condición instrumental e improvisatoria del jazz}

El jazz no ha sido, desde luego, ajeno a esta hibridación prácticamente inmemorial entre música y texto cuyo vehículo por excelencia es la canción ${ }^{8}$. Pero, a pesar de tener una rica y popular tradición vocal desde sus inicios, el jazz instrumental ha predominado tanto en grabaciones como en directo a través de conciertos y jam sessions. Hemos de considerar, por tanto, dos factores clave que condicionan la producción de cualquier discurso audiovisual asociado al jazz. El primero es, como resulta obvio, su propia naturaleza instrumental. La música instrumental forma parte de nuestro universo simbólico,

\footnotetext{
${ }^{5}$ Un ejemplo paradigmático es «Brianstorm» (Arctic Monkeys, 2007), con tres espacios narrativos diferenciados: la interpretación por parte del grupo, las imágenes que se superponen y las coreografías de un grupo de bailarinas.

${ }^{6}$ Además, el videoclip ha desarrollado un lenguaje propio (cambio de planos, movimientos de cámara, efectos visuales) al que nos referiremos más adelante.
}

${ }^{7}$ En el sentido estricto de enunciado oral o escrito, que se conoce coloquialmente como «letra» en el caso de la música.

8 Más extraños son casos como las óperas jazzísticas como Blue Monday (1922) y Porgy and Bess (1935), ambas de Gershwin. 
pero no de una manera esencialmente narrativa ${ }^{9}$, pues su eje no es un relato - aunque pueda ser interpretado así por el oyente-. A pesar de ello es cierto que el jazz tiene, a diferencia de algunas corrientes de abstracción pictórica o escultórica, elementos vagamente programáticos. Estos se ven reflejados en los títulos de las piezas, que varían entre la expresión de sentimientos («All the things you are», «There is no greater love», «Just friends»), los nombres propios de personas («Mr. P.C.», «Naima», «Beatrice»), lugares («52nd Street Theme», «Indiana», «Central Park West») o cosas («Footprints», «Impressions», «Oleo»), entre otros. Desde luego, algunos de estos títulos - especialmente aquellos que provienen de musicales de Broadway, algo habitual— se corresponden con un texto - una letra, en lenguaje común-que desaparece en su interpretación instrumental, por lo que el oyente a menudo la desconoce.

Excepcionales son los casos en los que, como Dexter Gordon, el músico lee el texto antes de interpretar instrumentalmente la pieza ${ }^{10}$. Y aunque el propio saxofonista afirmaba que conocer el texto original te hace entender y transmitir mejor la música ${ }^{11}$, la inmensa mayoría de composiciones a partir del bebop son instrumentales y, por tanto, carecen de texto. Esto puede relacionarse con la voluntad del bop de transcender el papel de música de consumo o entretenimiento y reivindicarse como una forma de arte instrumental (Tirro, 2007: 15). Además de remitir a la noción de «música pura» del Romanticismo, que filósofos como Hegel o Schopenhauer privilegiaron sobre el resto de artes ${ }^{12}$, la música instrumental está unida a cierto relato de la estética contemporánea en el que, como resume Rancière

\footnotetext{
${ }^{9}$ Un paradigma aparte lo constituyen aquellas músicas programáticas acompañadas de un texto narrativo, como es el caso de las sinfonías programáticas del romanticismo musical.

${ }^{10}$ Citado en: http://www.jazzweekly.com/2013/01/dexter-gordon-night-balladsmontreal-1977/

${ }^{11}$ "When you know the lyrics to a tune, you have some kind of insight as to it's composition. If you don't understand what it's about, you're depriving yourself of being really able to communicate this poem» Citado en https://www.learnjazzstandards.com/blog/ learning-jazz/jazz-advice/learn-lyrics-jazz-standards /

${ }^{12} \mathrm{Al}$ respeto es interesante Castrillo, D. y Martínez, F.J. (1996), «La metafísica de la música, Schopenhauer, Wagner y Nietzsche», Boza, V. (ed.), Historia de las ideas estéticas y de las teorías artísticas contemporáneas, Madrid: Visor, p 355-364.
}

(2012: 86), —la retirada de la mímesis es comparada a una insurreción por la cual las artes, desde hace un siglo, se habrían liberado de la obligación representativa y se habrían encontrado al fin con lo propio del arte, condenado hasta entonces a ser un instrumento de un fin externo- De esta manera, la música instrumental potenciaría a través de esta autonomía su material específico, liberada de toda analogía con el lenguaje o función subalterna respecto a un texto. El carácter instrumental de la mayor parte del jazz supone, por tanto, una problemática bifronte en cuanto a su relación con el discurso audiovisual. Por un lado, debido a la ausencia de texto que pueda sugerir o relacionarse con este discurso y, por otro, al vínculo entre asemanticidad y autonomía artística, a la que simbólicamente se renunciaría al superponer a la música un relato audiovisual. Para entender esto basta echar un vistazo a la producción audiovisual de Robert Glasper, compuesta mayoritariamente por performance videos ${ }^{13}$ y en la que los pocos videoclips tienen vocalista y texto, como «Calls» (Robert Glasper Experiment y Jill Scott, 2013) o «Maiysha» (Robert Glasper y Erykah Badu, 2016).

Estrechamente ligado al anterior, existe otro factor que condiciona también la relación entre jazz y audiovisual. Nos referimos al elemento improvisatorio, esto es, la creación espontánea basada en los materiales (melódicos, armónicos o rítmicos) de la composición. De forma análoga a la estética moderna, en el jazz ocupan lugares centrales valores como la originalidad, la innovación o la autenticidad. En resumen, la improvisación en el jazz tiene en cuenta especialmente la capacidad del intérprete para improvisar de acuerdo a cierto canon, distinto en cada «dialecto» del jazz (trad, swing, bop o free, por ejemplo), pero de una manera personal y sincera. Estos dos elementos problemáticos por su subjetividad, la personalidad y la sinceridad, configuran la noción de autenticidad. Para entenderlo, basta compararlo con los solos instrumentales del rock, otro género en el que la autenticidad (entendida de forma sensiblemente diferente) también es muy tenida en cuenta. Frente a los so-

\footnotetext{
${ }^{13}$ La ya mencionada serie Live at Capitol (2015) es el ejemplo más conocido.
} 


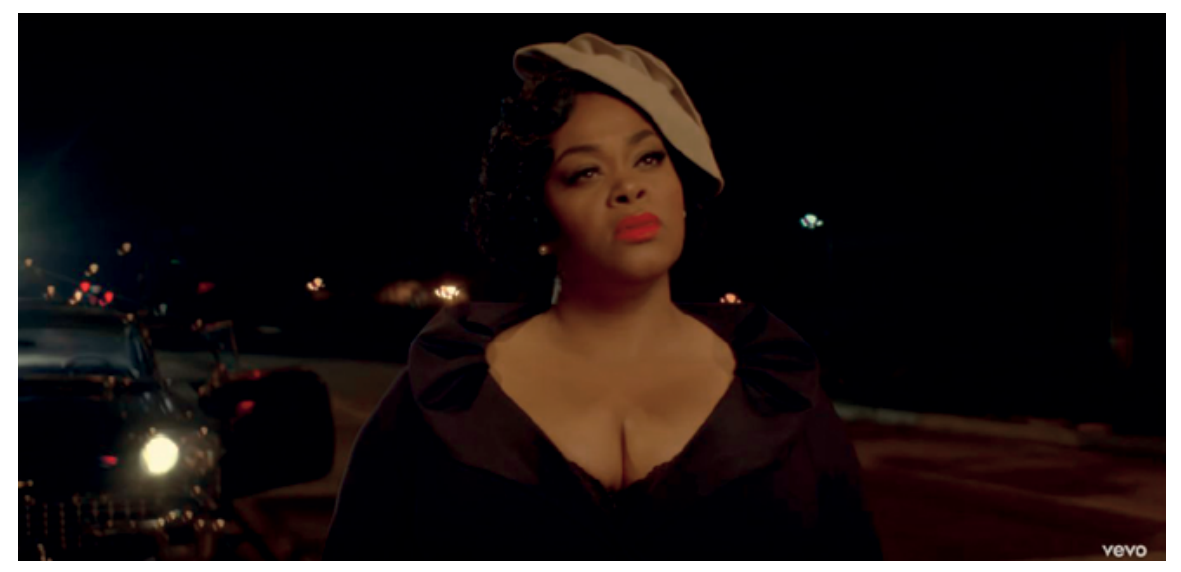

«Calls» (Robert Glasper y Jill Scott, 2013).

los del jazz, que el oyente espera que sean esencialmente inéditos, el oyente de rock reconoce aquellos solos célebres por las grabaciones («Highway Star» de Deep Purple o «Sultans of swing» de Dire Straits) que espera escuchar, sin variaciones importantes, en los conciertos de esos intérpretes o de aquellos grupos que los homenajean.

A diferencia de una actuación grabada, que incluso se ha institucionalizado en formatos como Live at o Unplugged, un videoclip es una manera de «fijar» cierta música, un procedimiento en principio contrario el carácter único que tiene un solo en jazz. Existe, además, un elemento técnico a tener en cuenta. $\mathrm{Al}$ aparecer un intérprete en el videoclip, este debe simular que toca o canta la música grabada previamente, algo mucho más sencillo para un vocalista o para el intérprete con una música establecida de antemano que para alguien que ha improvisado lo que finge interpretar. Un ejemplo claro puede ser el videoclip de «Sing Soweto» (Terence Blanchard, 1991), en el que el trompetista debió memorizar el tema íntegro con el solo incluido, algo sencillo en este caso debido al carácter reposado de la pieza, pero que sería bastante más costoso en el de un tema de tempo más rápido. A pesar de ello, en el videoclip se aprecia cómo la cámara evita a Blanchard en ciertos pasajes de notas rápidas (fundamentalmente adornos), de ejecución más precisa. Estos dos factores, su carácter instrumental e improvisado (con todas aquellas inferen- cias que hemos comentado anteriormente), contribuyeron de manera decisiva a que el jazz se distanciara cuando el videoclip empezó a ofrecer un relato paralelo al contenido musical.

\section{El discurso del jazz neoclásico}

Además de los factores propiamente musicales, no debe perderse de vista el discurso cultural que redefinió al jazz durante la década de 1980 y que afectaría tanto su producción como su recepción. Si en 1982 el grammy en la categoría «Best Improvised Jazz Solo» lo recibió Miles Davis con We want Miles, disco de fusión con gran carga funk, resulta muy ilustrativo constatar que los tres siguientes de la categoría (en 1983, 1984 y 1985) los ganara consecutivamente Wynton Marsalis (Think of One, Hot House Flowers y Black Codes) con un jazz de orientación diametralmente opuesta que llegaría a dominar no solo la industria, sino el propio discurso del género. La primera mitad de la década de 1980 presenciaría el ascenso de una manera de hacer y concebir el jazz, llamada «neotraditionalism», «neobop», o «neoclassical», que musicalmente reelaboraba los elementos centrales del bebop y el hard bop (con ciertas variaciones como las aportaciones modales de la década de 1960) y renunciaba a las innovaciones producidas a partir del freejazzpara 
volver sobre los formatos acústicos clásicos. Este movimiento neoclásico rescató la idea romántica del genio atormentado que se refleja en películas del momento, tanto documentales (Let's get lost [Bruce Weber, 1988], Straight, no chaser [Charlotte Zwerin, 1988]) como biopics (Bird [Clint Eastwood, 1988], Round midnight [Bertrand Tavernier, 1986] $)^{14}$, pero paradójicamente potenciaría la idea de un músico educado y virtuoso muy cercano al de la música académica, lo que coincidió con su entrada tanto en las instituciones culturales (Jazz at Lincoln Center) como en las de enseñanza a través de institutos, centros universitarios y conservatorios. Puede decirse que el jazz neoclásico heredó la voluntad artística del bebop a la que el jazz fusión parecía haber renunciado y lo convirtió definitivamente en una forma respetable de arte intelectualizado y perteneciente a la alta cultura, como explicó detalladamente Nicholson (1995).

Al mismo tiempo y de forma complementaria, se presentaban imágenes como las de The Cosby Show (Ed Weinberger, 1984-1992), una sitcom protagonizada por una familia afroamericana de clase media-alta, que presentaba como invitados a músicos de jazz (Dizzy Gillespie, Max Roach o Art Blakey), lo que contribuiría a vincular el jazz con cierta aspiración social y económica en oposición al rap, ascendente en esos años y retratado tanto de manera marginal o violenta (en películas como Boyz, $n$ the Hood [John Singleton, 1991], South Central [Stephen Milburn Anderson, 1992] o Juice [Ernst Dickerson, 1992]) como caricaturesca (el papel de Will Smith y sobre todo de Jazz en The Fresh Prince of Bel-Air [Andy y Susan Borowitz, 1990-1996]) ${ }^{15}$. El jazz, convertido como hemos dicho en una forma respetable de alta cultura, necesitaba conservar y fortalecer valores como la autenticidad para reforzar este giro. Es precisamente en este momento cuando surge MTV, que institucionalizará el formato del videoclip contemporáneo. Dado que el videoclip es, en última instancia, un producto de

\footnotetext{
${ }^{14}$ La película Mo’ Better Blues (Spike Lee, 1990) es, quizá, una de las pocas piezas audiovisuales de la época que retrata el jazz contemporáneo (la banda sonora la compuso Brandford Marsalis, hermano de Wynton Marsalis) situándolo cercano a la cultura de la calle, de manera similar a músicas como el rap. El videoclip de la pieza homónima recoge diversas escenas y diálogos de la película.

${ }^{15}$ Esto es explicado con más detalle en Williams (2010: 437-440.
}

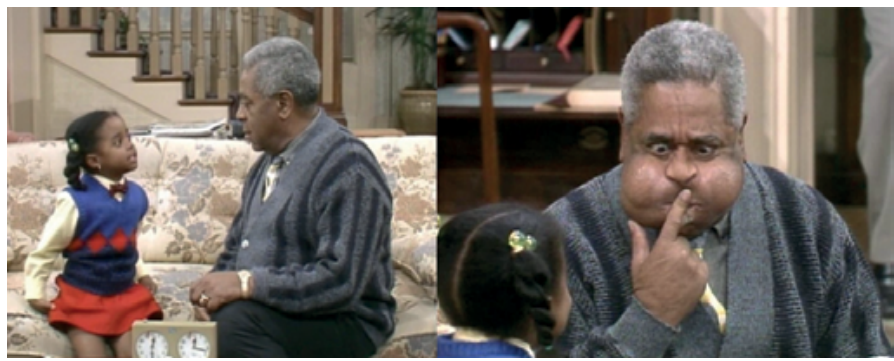

Aparición de Dizzy Gillespie en The Cosby Show (Ed Weinberger, 1984-1992).

marketing, es natural que el jazz neoclásico no mostrara especial interés por un formato que podría suponer una renuncia simbólica, como hemos dicho, tanto a la autonomía de la expresión musical «liberada del texto o la imagen» como a su propia autenticidad ${ }^{16}$. En esta situación, el jazz llegará a una bifurcación tanto musical como audiovisual que se definirá en la intersección con dos discursos, el del pop y el del rap, que examinaremos brevemente a continuación de una manera más cercana a la enumeración glosada que al análisis.

\section{El pop como síntoma}

Al hablar de música pop tenemos un problema similar al planteado inicialmente con el jazz. Es posible que, más que como un género, pueda sernos útil entender el pop como el indicio de cierta vocación masiva o sensibilidad melódica. La vocación masiva, esto es, cierta voluntad expansiva o de contagio, limita sus elementos experimentales y configura una tipología musical —la del formato canción - prácticamente siempre dependiente o vinculada a un texto, por lo que en ocasiones llega a asumir cánones creados en la primera mitad del siglo XX. La sensibilidad melódica, estrechamente ligada a lo anterior, se manifiesta en melodías con tendencia a la sencillez — sin grandes saltos o intervalos disonantes_-, armonías análogas — direcciones y cadencias claras - y ritmos regulares y con tendencia a la simetría.

\footnotetext{
${ }^{16}$ A pesar o precisamente por ello, el jazz ha adoptado, especialmente desde la llegada de YouTube, el performance video como formato audiovisual preferente, como puede comprobarse en la mayoría de canales de sus intérpretes.
} 


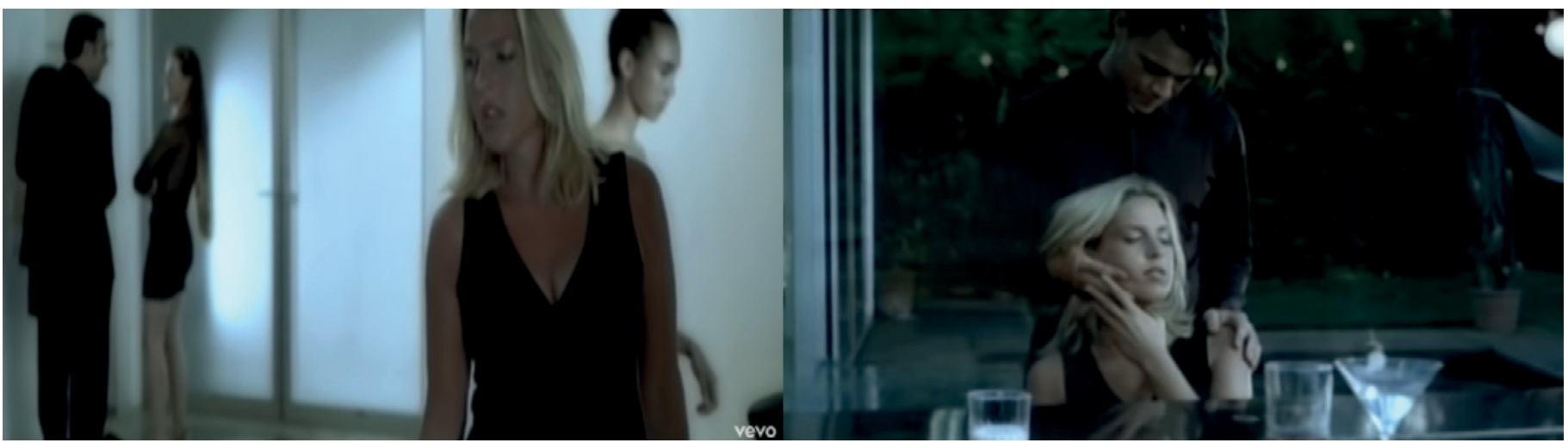

Fotogramas de «Let's face the music and dance» (Diana Krall, 1999).

Esta concepción amplia del pop hace que pueda observarse como indicio o síntoma en multitud de géneros musicales que van desde el bolero o el rocksteady al reggaetón además, por supuesto, de la producción musical a la que tradicionalmente se conoce con ese nombre, de los Beatles a Britney Spears.

Como hemos dicho, el formato canción siempre ha formado parte del jazz a través de standards provenientes del teatro musical, por lo que cierta simbiosis con el pop es natural. Así puede observarse en uno de las artistas de jazz con vocación pop más conocidas: Diana Krall. «Let's face the music and dance» (1999) es un conocido standard que ha sido interpretado tanto instrumentalmente por músicos más ortodoxos (Jackie McLean, Paul Motian o Dave O'Higgins) como vocalmente $^{17}$ (Ella Fitzgerald, Anita O'Day o Frank Sinatra). Musicalmente, la versión de Diana Krall opta por un enfoque cercano al easy listening con ritmo de bossa nova, en las antípodas de otras versiones vocales como las de Sheila Jordan o las más actual de Cécile McLorin Salvant. $\mathrm{El}$ videoclip muestra a la cantante y pianista paseándose por una fiesta poblada por parejas en actitudes cariñosas mientras interpreta el tema. Tras salir y sentarse en un piano, aparece finalmente un hombre que la besa. Podemos decir que el videoclip presenta cierto relato, pues tras vagar de manera solitaria por la fiesta acaba

17 Originalmente es una canción con texto, pues forma parte de la película musical Follow the fleet (Mark Sandrich, 1939). encontrando el romance al que hace referencia el texto de la canción («So while there's moonlight and music and love and romance / Let's face the music and dance»). Ni temática ni visualmente presenta aportaciones relevantes, en un contexto en el que la música pop introducía novedades en los videoclips (en ese mismo año, 1999, se producen videoclips renovadores como «Let forever be» [The Chemical Brothers] o «Praise you» [Fatboy Slim]). De esta manera, «Let's face the music and dance» bien podría ser una versión amable de los videoclips de «Genie in a bottle» (Christina Aguilera) o «Heartbreak Hotel» (Whitney Houston), también del mismo año. Lo mismo puede decirse de «The look of love» (Diana Krall, 2001), lanzado un par de años después y cuyo mayor aliciente es que el vídeo es «proyectado» en carteles por la calle, un recurso presente en videoclips anteriores como «Kiss me» (Sixpence None The Richer, 1997).

Esta será la tónica habitual del jazz más cercano al pop: la adopción de sus modelos más tradicionales eludiendo audacias narrativas o visuales. En ese sentido, puede afirmarse que el jazz de apariencia pop es más conservador audiovisualmente que el propio pop, habitualmente pendiente de incorporar innovaciones o elementos llamativos en sus videoclips. Esto puede observarse, por ejemplo, en los videoclips de «Breakdown» (2018) y «Don't need the real thing» (2018), ambos de Kandace Springs. Publicados en 2018, ya en plena mayoría de edad del videoclip, vuelven a ser muestras audiovisuales del pop más tradicional. En el caso de «Break- 
down», un mero tránsito de escenarios y atuendos. En el de «Don't need the real thing», la presentación de un relato escuálido que tiene lugar en el interior de un coche. La contrapartida a este último podría ser «Changing all those changings» (Madeleine Peyroux, 2013), que también transcurre principalmente en un vehículo pero a cuyo desarrollo dotan de interés, a pesar de carecer de un relato claro, planos recurso o subjetivos, movimientos de cámara inusuales o cierta complicidad de la cantante. Algo parecido sucede en «I'm allright» (2006) o «On my own» (2018), en la que su efectividad como videoclip pop vuelve a depender casi exclusivamente de unos pocos hallazgos visuales y la complicidad de Madeleine Peyroux.

En la producción audiovisual de Jamie Cullum, otro importante crossover del jazz pop, encontramos videoclips colindantes con el performance video como «Love is in the picture» (2018), pero también casos más interesantes como «Everlasting love» (2003), que combina su interpretación en un plató en el que podemos ver los propios elementos de la grabación (cámaras, pantallas, focos, raíles para el dolly o miembros del equipo) con planos de la película Bridget Jones: The edge of a reason (Beeban Kidron, 2004), de cuya banda sonora formó parte. También supone cierta novedad el videoclip de «I'm all over it» (2009), que explota situaciones cómicas en un hotel en el cual el cantante aparece vestido de botones, una narrativa clásica en el pop que tiene precedentes en «Candyman» (Christina Aguilera, 2006) o «Toxic» (Britney Spears, 2003), en los que las cantantes aparecen caracterizadas en diferentes contextos llamativos.

Podría decirse que los relatos de los videoclips de Gregory Porter y Melody Gardot sintetizan algunas de las principales tendencias del jazz de enfoque pop y su perfil conservador. En «Hey Laura» (Gregory Porter, 2013) aparecen los clichés habituales de una película romántica, mientras que «Baby I'm a fool» (Melody Gardot, 2009) bebe de los musicales clásicos, con un homenaje a las coreografías de Busby Berkeley. Por otro lado, tanto «Be good (Lion's song)» (2012) y «Consequence on love» (Gregory Porter, 2016) como «Preacherman»

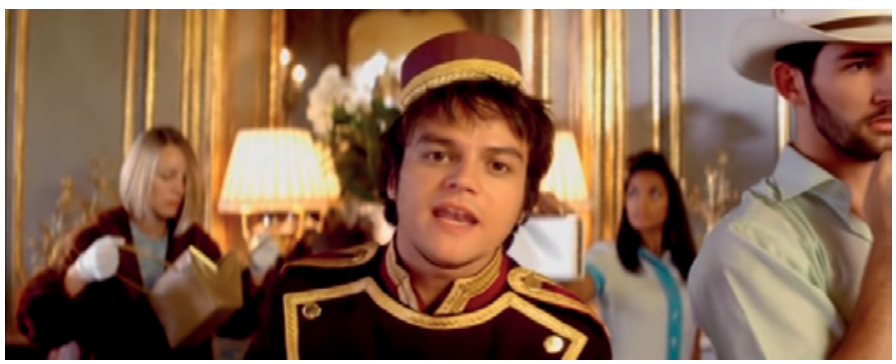

«I'm all over it» (Jamie Cullum, 2009).

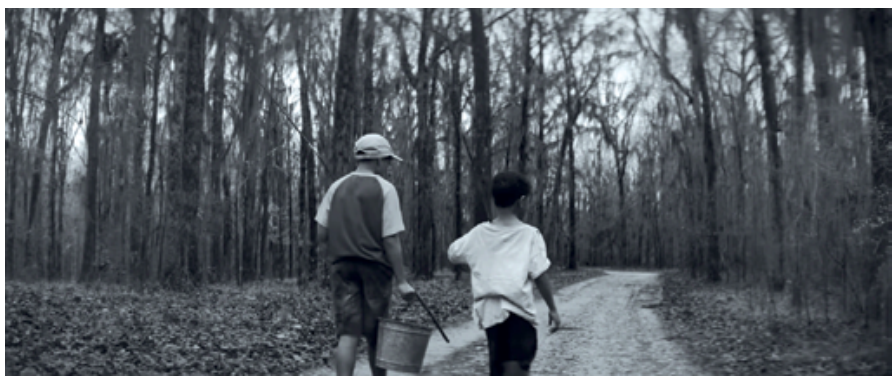

«Preacherman» (Melody Gardot, 2015).

(Melody Gardot, 2015) plantean relatos elaborados con puntos de contacto con el cortometraje, algo habitual en la actualidad. En el caso de «Mira» (Melody Gardot, 2012), evocación exótica de Latinoamérica, es imposible no ver cierta vampirización o colonialismo estético. Por otra parte, frente a «Same to you» (Melody Gardot, 2015), que propone un relato fragmentario con ciertas innovaciones visuales, resulta sintomático que «La vie en rose» (Melody Gardot, 2012) se grabara como vídeo de campaña de la marca de joyería Yves Piaget, lo que explica su acentuada atmósfera kitsch.

\section{Encrucijadas con el rap}

La influencia no solo del rap, sino de toda la cultura hip hop — de la que también forman parte el breakdance, el graffiti y el djing - ha sobrevolado el jazz desde mediados de la década de 1980, como atestiguan los movimientos M-Base y el acid jazz — ambos de contornos difusos - y grabaciones como Doo-Bop (Miles Davis, 1991), Music evolution (Buckshot LeFonque, 1997) o Dis is da drum (Herbie Hancock, 1995). Entre el jazz y el 


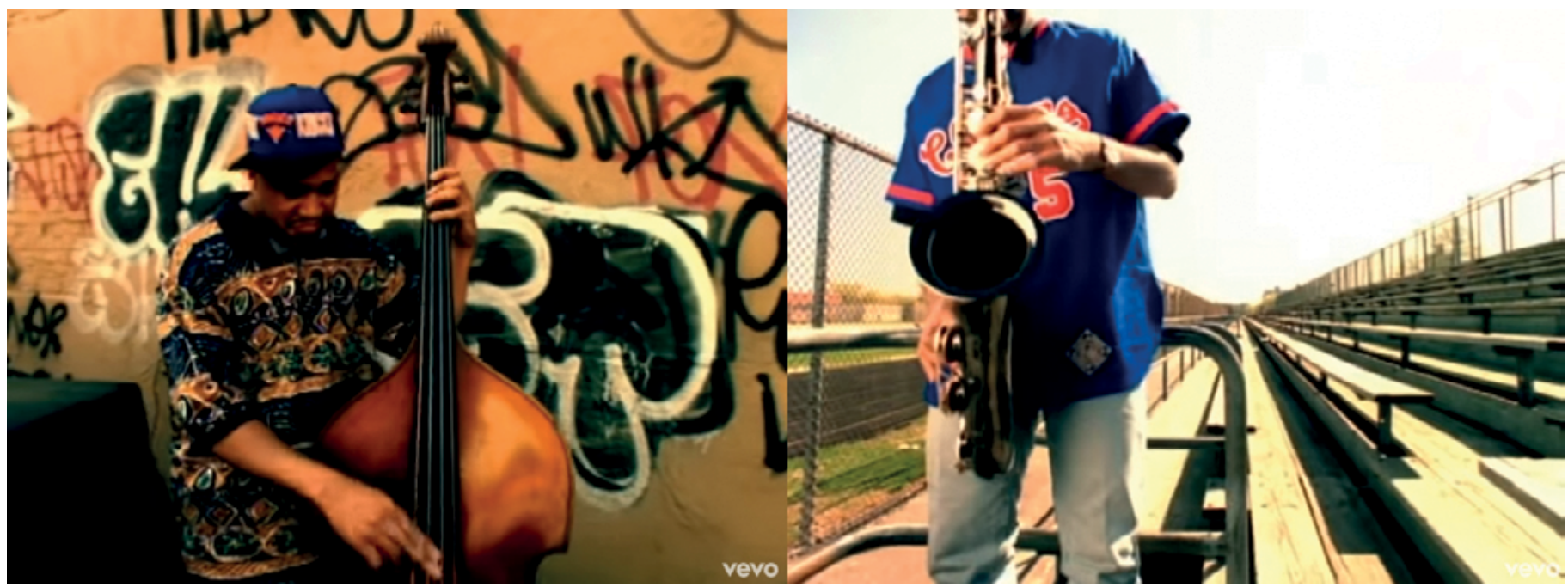

Dos fotogramas de «Breakfast at Denny's (Uptown Version) (Buckshot LeFonque, 1995).

rap, músicas de ascendencia afroamericana, se produce una relación de simbiosis más clara que en el caso del pop. El rap se nutre de la tradición musical afroamericana a través de samples, algo que le dota de un sonido orgánico y de cierta aura de autenticidad, mientras que el jazz obtiene esta autenticidad de la actualidad de una música proveniente de «la calle», además de nuevos ritmos y posibilidades expresivas. Además, ambas tienen en común su elemento improvisatorio y agonístico, desarrollado por el jazz en las jam sessions y por el rap en las freestyles battles. Dado que la significación que el rap recoge del jazz tiene literatura bastante exhaustiva al respecto (Williams, 2010) nosotros nos referiremos a la dirección contraria, del rap hacia el jazz, en el terreno del videoclip.

Quizá el territorio más conocido entre las fronteras del jazz y el rap es el movimiento M-Base, corriente heterogénea surgida en Nueva York en la década de 1980 que amalgamaba cierta filosofía particular respecto a sus ideas musicales y compositivas y un decidido interés por incorporar sonidos del momento como el rap $^{18}$. Esta influencia permeó al terreno visual, por lo que en los videoclips de artistas como Greg Osby podemos observar la influencia directa de los videoclips

\footnotetext{
${ }^{18}$ Esto hizo que Perico Sambeat definiera el sonido como la «fusión de ritmos raperos con un fraseo poscoltraneano» (Ménsua, 1995: 15).
}

de rap del momento. Es lo que sucede en «Raise» (Greg Osby y C.L. Smooth, 1993) en el que además de la participación de un rapero, cosa habitual en este movimiento, la estética tiene conexiones evidentes con videoclips de rap de ese mismo año como «Shit is real» (Fat Joe) o «Electric Relaxation» (A Tribe Called Quest ${ }^{19}$ ). Otro ejemplo claro es «Mr. Gutterman»(Greg Osby con Bad Newz y Mustafo, 1993), cuyas imágenes tienen semejanzas patentes con videoclips de rap de la época como «C.R.E.A.M.» (Wu-Tang Clan, 1993)o «Shook ones» (Mobb Depp, 1995). Otro ejemplo de amalgama del jazz y rap en ese momento lo constituyó el grupo Buckshot LeFonque, fundado por Brandford Marsalis y que reunía a productores y raperos (Dj Premier y 50 Styles: The Unknown Soldiers) con músicos de jazz (El propio Brandford Marsalis, Russell Gunn o Joey Calderazzo). Aunque vídeos como «Music Evolution» (Buckshot LeFonque, 1997) siguen mostrando paralelismos notables con los del rap del momento, quizá el caso más interesante es el de «Breakfast at Denny's (Uptown Version)»(Buckshot LeFonque, 1995). Esto se debe a que fue dirigido por Spike Lee, por lo que además de vincularse a videoclips de rap también dirigidos por él — «Fight the Power» (Public Enemy, 1990) o «Revolu-

${ }^{19}$ Grupo de rap a su vez muy influido por el jazz. 
tion» (Arrested Development, 1992) — el vídeo exhibe parecidos naturales con películas del director de esa época como Crooklyn (1994) o Clockers (1995).

En la introducción nos hemos referido a algunos videoclips de Robert Glasper y a su contenido textual a diferencia de otros performance videos de carácter instrumental. «Maysha» (con Erykah Badu, 2016) es casi un performance video que juega con el hecho de ser un plano secuencia y «Calls» (Robert Glasper Experiment con Jill Scott, 2013) es más una sucesión de situaciones encadenadas que un relato de exposición clara, aunque esto se compensa con la estética cuidada, el magnetismo de Jill Scott y la atracción generada por las situaciones. Ese interés por vídeos más conceptuales cuya fuerza es más estética que narrativa también caracteriza la producción audiovisual de Kamasi Washington. Es el caso tanto de «Hub-tones» (2018), un plano fijo de nueve minutos con variaciones en el zoom que resulta hipnótico, como de «Street Fighter Mas» (2018), que propone un recorrido narrativo relativamente claro pero de contenido surrealista.

Vale la pena realizar algunos apuntes sobre la escena de jazz británica. Las primeras influencias del rap se hicieron notar en la escena acid jazz, que recogía también elementos musicales del rap. «Cantaloop (Flip Fantasia)» (US3, 1993) fue fundacional en este sentido y maneja diversos recursos visuales (secuencias proyectadas hacia atrás, claroscuros, televisiones emitiendo) que acabarían siendo lugares comunes del videoclip de la época. En el caso de Lady Day (\& John Coltrane) (Courtney Pine, 2000) la influencia musical no proviene del rap, sino de la música jungle o drum and bass británica, pero su estética sí que presenta importantes paralelismos con ciertos videoclips de rap rodados en clubs, como «The Next Episode» (Dr. Dre con Snoop Dogg, Kurupt y Nate Dogg, 1999) o «Get it on the floor» (DMX, 2003). En la actualidad van surgiendo propuestas interesantes como «Pineapple» (Blue Lab Beats con Moses Boyd y Nèrija, 2018), influido por la estética documental de películas como Kids (Larry Clark, 1995), o «Oooo Lala» (Blue Lab Beats, 2018), que propone una coreografía extravagante y descontextualizada similar a videoclips

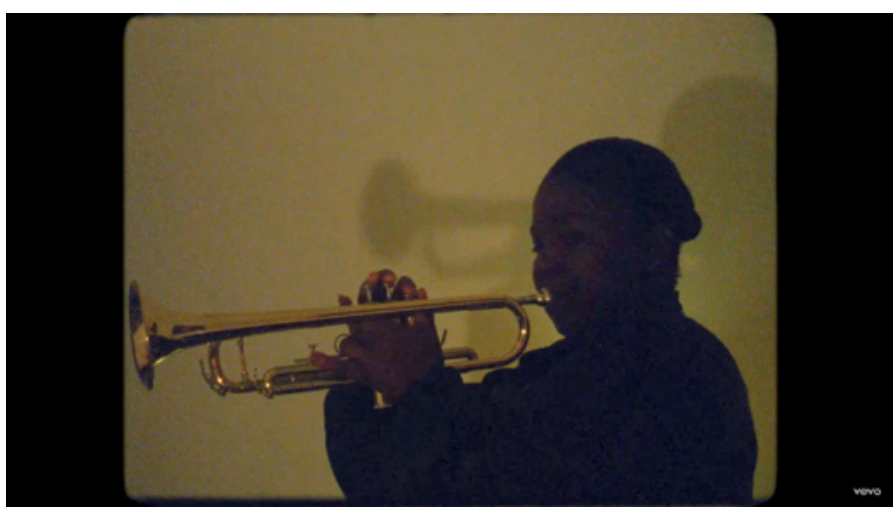

«Pineapple» (Blue Lab Beats con Moses Boyd y Nèrija, 2018).

como «Here it goes again» (OK Go, 2005) o «Weapon of choice» (Fatboy Slim, 2000) ${ }^{20}$. La influencia del rap también es clara tanto en la música como en los videoclips de Kamaal Williams, del cual puede destacarse «New Heights (Visions of Aisha Malik)» (2019), que integra coreografías de artes marciales en una atmósfera extraña cercana a la sugerida por Kamasi Washington en «Street Fighter Mas» (2018).

A modo de conclusión podemos sugerir que los videoclips de jazz influidos por el rap son estrictamente contemporáneos. Es decir, que se sitúan en las mismas coordenadas estéticas que el resto de videoclips de su momento, a diferencia de la actitud conservadora del jazz más influido por el pop. Con la inabarcable diversidad de estilos de jazz — casi más un lenguaje o una familia de dialectos que un género musical- del siglo XXI, sus incursiones en el videoclip son cada vez más frecuentes y variadas, lo que ha generado videoclips sobresalientes que no caben en ninguna de las categorías anteriores. Destacan, por ejemplo, «Little Song for Mankind» (Jasper Høiby, 2016), «The prophet is a fool» (Brad Mehldau, 2019) o «Summer Goddess» (Soil \& Pimp Sessions, 2008). No cabe duda de que esta renovación aún está por dar sus mejores frutos.

\footnotetext{
${ }^{20}$ También el videoclip de «Bahia Dreamin’ (Karriem Riggins), cuya música está influida también por el rap, juega con este tipo de elementos.
} 


\section{Bibliografía}

Castrillo, D. y Martínez, F. J. (1996), «La metafísica de la música, Schopenhauer, Wagner y Nietzsche», Bozal, V. (ed.), Historia de las ideas estéticas y de las teorías artísticas contemporáneas, Madrid: Visor, págs 355-364.

Formaggio, D. (1976), Arte, Barcelona: Labor.

Gaudreault, A. y Jost, F. (1995), El relato cinematográfico. Ciencia y narratología, Barcelona: Paidós.

MénsuA, V. (1995), «Blindfold Test: Perico Sambeat», Cuadernos de jazz, 30,p. 14-18.
Nicholson, S. (1995), Jazz: The 1980s Resurgence, New York, Da Capo Press.

RANCiÈre, J. (2012), El malestar en la estética, Madrid: Clave Intelectual.

Tirro, F. (2007), Historia del jazz moderno, Barcelona: Robinbook.

Williams, J. A. (2010) «The construction of jazz rap as high art in hip-hop music», The Journal of Musicology, 27(4), págs 437-440. 
Ediciones Siruela BIBLIOTECA DE ENSAYO
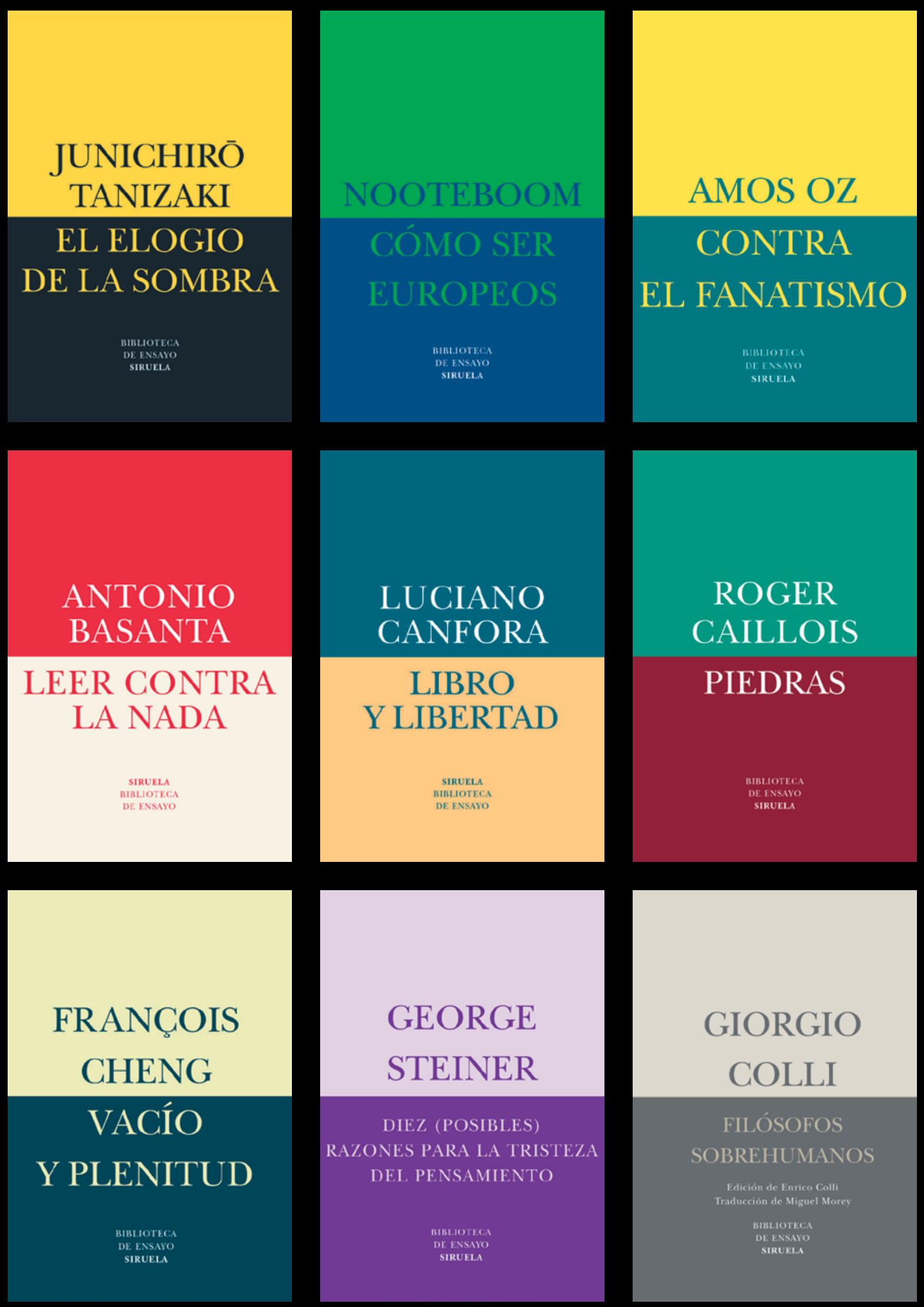